International Journal of Engineering \& Technology, $9(1)(2020) 175-181$
International Journal of Engineering \& Technology
SPC
Website: www.sciencepubco.com/index.php/IJET
Research paper

\title{
In situ diagnostic assessment for the infiltration rate of the northern Gaza wastewater infiltration basins
}

\author{
Mazen Abualtayef ${ }^{1 *}$, Thaer Abushbak ${ }^{2}$, Ahmed Abu Alnoor ${ }^{3}$, Hassan Al-Najjar ${ }^{4}$ \\ ${ }^{1}$ Environmental Engineering Department, the Islamic University of Gaza, Palestine \\ ${ }^{2}$ Central Laboratory for Water and Soil, Ministry of Agriculture, Palestine \\ ${ }^{3}$ Engineering Department, Abo Moailq Contracting Company, Palestine \\ ${ }^{4}$ Civil Engineering Department, Institute of Natural Sciences, Sakarya University, Turkey \\ *Corresponding author E-mail: mabualtayef@iugaza.edu.ps
}

\begin{abstract}
The Northern Gaza Emergency Sewage Treatment (NGEST) is addressed as a promising water management intervention strategy to maintain the sustainability of groundwater aquifer in the Gaza Strip. This study assesses the current operational status of the north-ern Gaza wastewater infiltration basins located at NGEST project. In situ diagnostic assessment was performed at two spots (A) and (B) located inside the basin (3). The results of sieve analysis and bulk density indicate that the soil at the spot (B) is finer than of spot (A) where the contents of the fine material and bulk densities were $13 \%$ and $1544 \mathrm{~kg} / \mathrm{m} 3$ at the spot (A) and $23.7 \%$ and $1544 \mathrm{~kg} / \mathrm{m} 3$ at the spot (B). In terms of the infiltration capacity, the nature of soil at the spot (A) exhibits better initial and saturated infil-tration rate in comparison to the soil at the spot (B), where the initial and saturated infiltration rates were 2.88 and 0.43 for spot (A) and 0.29 and 1.73 meters per day for spot (B), respectively. Thus, the diagnostic assessment for the northern Gaza wastewater infil-tration basins indicates that the soil classification is silty sand and the infiltration rates range between about 3 and 0.3 meters per day.
\end{abstract}

Keywords: Gaza Strip; Infiltration; Treated Wastewater; Groundwater; Sustainability.

\section{Introduction}

The region of the Middle East and North Africa (MENA) is classified as a severe water crisis area due to the limitation of water resources and climatic drought. Depending on the estimations of the water management and monitoring system, the area of the Gaza Strip is addressed as one of the most water scarcity areas that need urgent intervention to manage the deficit in the water balance. The groundwater aquifer is the only available water resource for the domestic, industrial and agricultural uses in the Gaza Strip. The groundwater aquifer shows significant signs of permanent overexploited status on the quantity and quality sides. The annual sustainable yield of the groundwater aquifer is between 55 and 60 million cubic meters; however, the abstraction rate is four times higher than the sustainable yield of about 200 million cubic meters per annum (PWA, 2015). Accordingly, the records of water balance show a severe and continuous deficit of about more than 120 million cubic meters per annum in the groundwater budget (PWA 2013). In terms of the groundwater quality, approximately more than $96 \%$ of the groundwater is grossly contaminated with water quality levels exceed the specified standards by the World Health Organization (WHO) for safe drinking water (WHO, 2006; PWA, 2014a). The monitoring program of the Gaza groundwater aquifer over the entire geographical extent of the Gaza Strip indicates that the content of nitrate $\left(\mathrm{NO}_{3}\right)$ reaches more than two to nine times higher than the WHO standards (Shomar et al., 2008). As well, the chloride (Cl) concentrations showed high levels between 250 and 1500 mg/l (PWA, 2014a). Despite the groundwater over-pumping, the water supply system of the Gaza Strip still suffers from a critical water supply deficit that is estimated by about 80 million cubic meters per year (Sami et al. 2011). The agricultural sector consumes the largest portion of nearly $50 \%$ of the entire pumped groundwater water from the aquifer among the other the remaining domestic and industrial sectors that tighter use the second half of the extracted groundwater. The agricultural sector in the Gaza Strip consumes between 75 and 80 million cubic meters of water annually pumped through more than 4000 water wells distributed over the governorates of the Gaza Strip (PWA, 2012; Al-Najar, 2011). Hence, in the light of the water sector deterioration in the Gaza Strip, new water resources should be introduced to overcome the gap in the water balance and to guarantee the sustainability of the groundwater aquifer (Sami et al. 2011). The water intervention management plan of stormwater (Abualtayef et al., 2017), seawater desalination (PWA, 2011; Abualtayef et al., 2019) and wastewater reuse that were adopted by the Palestinian water authority (PWA) may maintain the integrity of the groundwater aquifer from the full failure (Seyam and Mogheir, 2010; PWA, 2014b). Reusing of the treated wastewater for the purposes of agricultural irrigation and replenishment of water resources is classified as a strategic option in the water management cycle to remediate the water crisis as well as to protect the water resources from further deterioration (Zhang and He, 2013; Jaramillo and Restrepo, 2017). The Palestinian Water Authority (PWA) and the World Bank investments suggest wastewater reuse programs as an indispensable solution for Palestine in general and the Gaza Strip in particular. The planned wastewater reclamation program aims at maintaining the sustainability of the groundwater by recharging the treated effluents into the 
aquifer through infiltration basins equipped with recovery wells and by modifying the natural conditions to enhance the infiltration efficiency (PWA, 2011). However, the main problem that currently faces the infiltration basins is characterized by the reduction in the infiltration efficiency and capacity due to the accumulation of the attached suspended solids and organic matters with treated wastewater in the soil pores. Therefore, in terms of infiltration capacity, this study focuses on assessing the current operational status of the artificial recharge of treated wastewater to groundwater in the Gaza Strip through the Northern Gaza Wastewater Infiltration Basins.

\section{Overview and description of the study area}

The Gaza Strip, shown in Fig. 1a, covers an area of $365 \mathrm{~km}^{2}$ which extends on the coast of the eastern Mediterranean with a length of about $42 \mathrm{~km}$ long and a width between 6 and $12 \mathrm{~km}$. The Gaza Strip is classified as a highly-populated area with a population reaches two million inhabitants (PCBS, 2017). Concerning the current situation of the water sector, the region of the Gaza Strip is characterized by many parties as an area in a continuous humanitarian crisis due to the lack of both quantity and quality of water resources for different uses (PWA, 2011, 2013, 2014). The project of Northern Gaza Emergency Sewage Treatment (NGEST) was introduced as an urgent intervention to cease the deterioration in the environment due to the arbitrary disposal of wastewater without previous treatment as well as to sustain the underlying groundwater aquifer from the complete depletion. The site of the NGEST, shown in Fig. 1a, is located at the North-Eastern part of the Gaza Strip at an elevation ranges between 50-70 meters above the mean sea level (MSL). The NGEST project comprises of two main parts:

i) The North-Gaza Wastewater Treatment Plant (NGWWTP) which is designed to treat wastewater with an ultimate capacity of 35,600 cubic meters per day and includes a secondary biological treatment with nitrogen removal, sludge treatment, digestion, dewatering, drying, and storage. The plant in the full operation stage will be able to treat wastewater by a capacity of $70,000 \mathrm{~m}^{3}$ per day (PWA, 2011).

ii) Nine Treated Wastewater Infiltration Basins which are implemented over an area of 8.1 Hectares as shown in Figure 1b. The design infiltration capacity of the basins is about $15,000 \mathrm{~m} 3$ daily; however, the current infiltration capacity of the basins is reduced to about half of the designed capacity due to many factors such as the bad effluent quality from the treatment plant and the high concentration of suspended solids in the effluent. The average infiltration rate for the basins is currently 0.59 meters per day compared to the designed infiltration rate of nearly 1.00 meter per day (PWA, 2012).

(A)

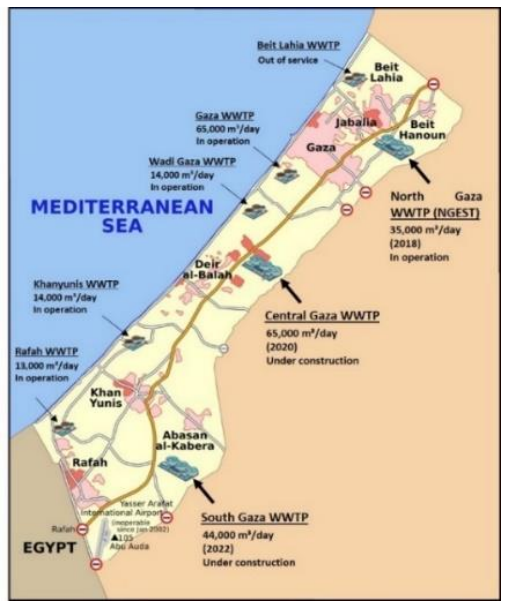

(B)

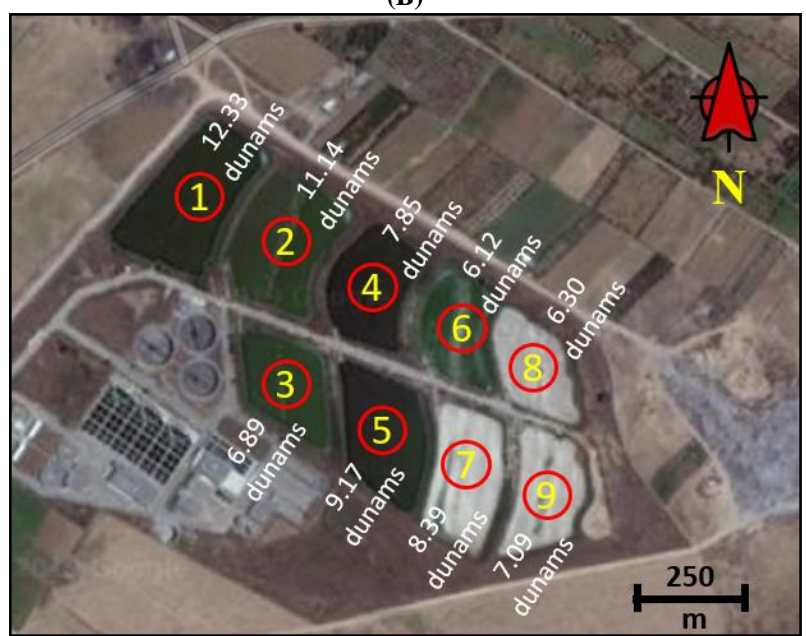

Fig. 1: The Locations of (A) the Gaza Strip; (B) the Infiltration Basins Location.

The operational scheme of the NGEST, shown in Fig. 2, consists of 27 recovery wells, two water reservoirs of $4,000 \mathrm{~m}^{3}$, booster pump station with $6,000 \mathrm{~m}^{3}$ per hour. The groundwater is pumped through collection pipelines from the recovery wells to the reservoirs. Trunkline and distribution system of $103 \mathrm{~km}$ length to pump the treated wastewater from the NGWWTP up the farms in order to irrigate 1,500 hectares of agricultural lands in Eastern-North of Gaza and Gaza city. The purpose of the recovery scheme is to capture and to monitor the expected pollution plume due to the infiltration process through the 27 recovery pumping wells. The design criteria for the NGWWTP were followed insistently to guarantee a treatment efficiency that could provide high quality treated wastewater according to the determinants of the Palestinian standard (PS, 2003). Hence, the Palestinian standard (PS) requires specific standard considerations to irrigate crops by the treated wastewater. The PS restricts the irrigation activities for gardens, playgrounds, and parks to be by a reclaimed wastewater quality of class (A). However, the processes of groundwater replenishment by infiltration and the offshore disposal of about $500 \mathrm{~m}$ into the sea should be by wastewater quality of not less than class (C). The standard permits the irrigation of crops of seeds production, dry feeds, forest trees, industrial crops and grains using low quality of treated wastewater (PS, 2003). 


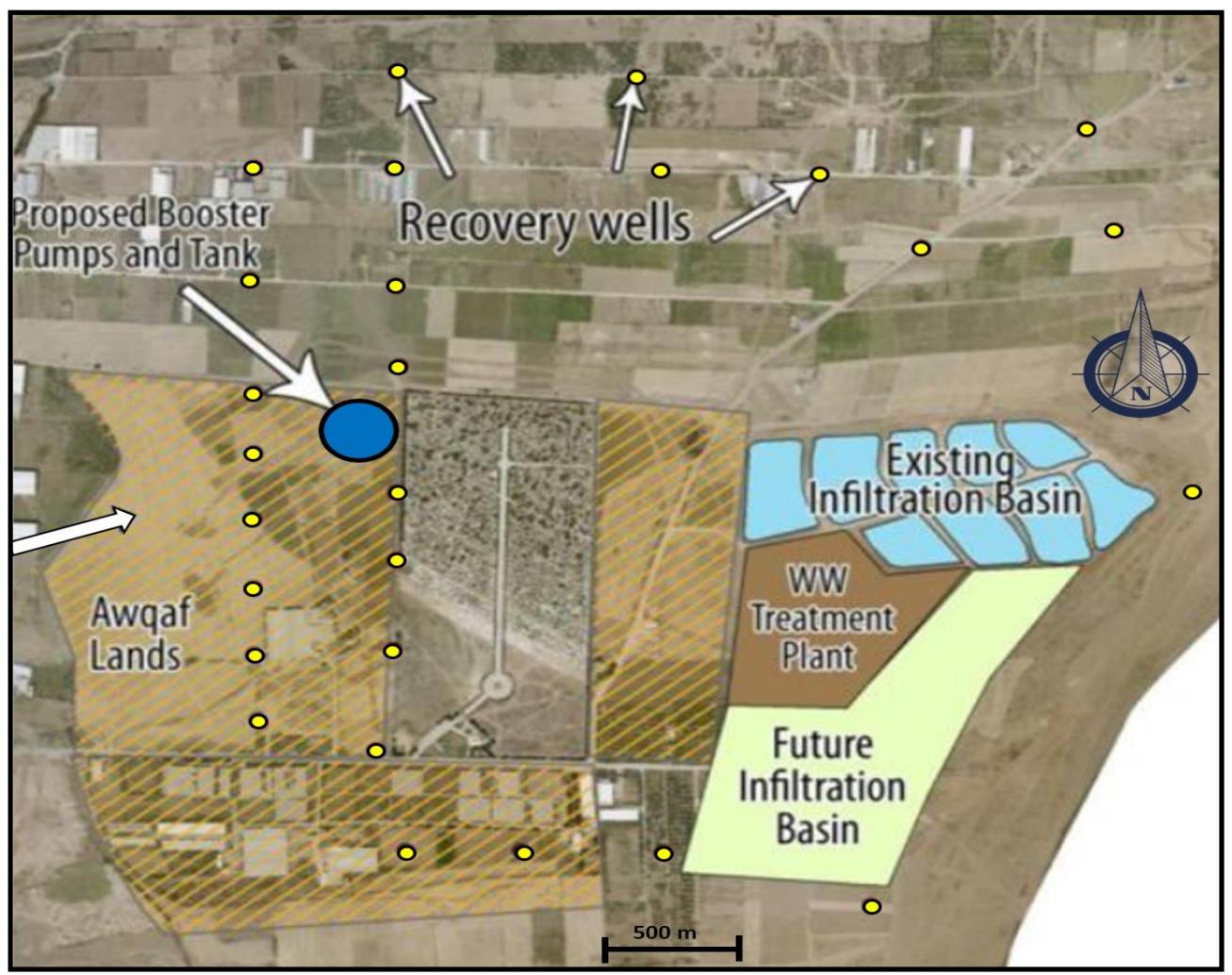

Fig. 2: The Operational Scheme of the NGEST.

The historical records for the different water quality parameters at the infiltration basins indicate that the efficiency of the NGWWTP is lower than the designated efficiency where the quality of the treated wastewater that is pumped to the infiltration basins does not meet the quality level of class (C) according to the PS. The change in the quality of the infiltrated treated wastewater as depicted in Table 1 forms a high load on the infiltration basins which as a result causes severe clogging in the bed of the infiltration basins. The periodic accumulation of the suspended solids of about $60-130 \mathrm{mg} / \mathrm{l}$ and biological oxygen demand (BOD 5 ) of about 60-95 mg/l from the partially treated wastewater acts negatively on the infiltration efficiency of the basins (PWA, 2016).

\begin{tabular}{lllll} 
& \multicolumn{5}{c}{ Table 1: The Quality of the Treated Wastewater (PWA, 2013) } \\
\hline Parameter & Unit & Palestinian Standard & Groundwater Quality & Effluent Water Quality \\
\hline BOD $_{5}$ & $\mathrm{mg} / 1$ & 40 & 3 & $60-95$ \\
TDS & $\mathrm{mg} / 1$ & 1,500 & 960 & 1,800 \\
TSS & $\mathrm{mg} / 1$ & 50 & - & $60-130$ \\
$\mathrm{NO}_{3}$ & $\mathrm{mg} / 1$ & 30 & 30 & $55-75$ \\
Faecal coliform & $\mathrm{CFU} / 100 \mathrm{ml}$ & 1,000 & nil & 1100 \\
\hline
\end{tabular}

The environmental assessment study in the region of NGEST has been performed by collecting a number of samples from the wells in the vicinity of the infiltration basins during December 2015 (PWA, 2016). The collected samples were analyzed for the parameters of Nitrate, BOD, TDS and chloride and the results were geographically mapped, shown in Fig. 3, to figure out the dispersion of contamination due to the infiltration activities. The environmental assessment indicates that there is significant contamination around the infiltration basins up to a distance of $1,000 \mathrm{~m}$ from the center of the infiltration area. The guidelines of the PS could be achieved at a distance of 1000 meters from the infiltration point where the nitrate, BOD, TDS, and chloride were $28,5,1100$, and $325 \mathrm{mg} / \mathrm{l}$, respectively.
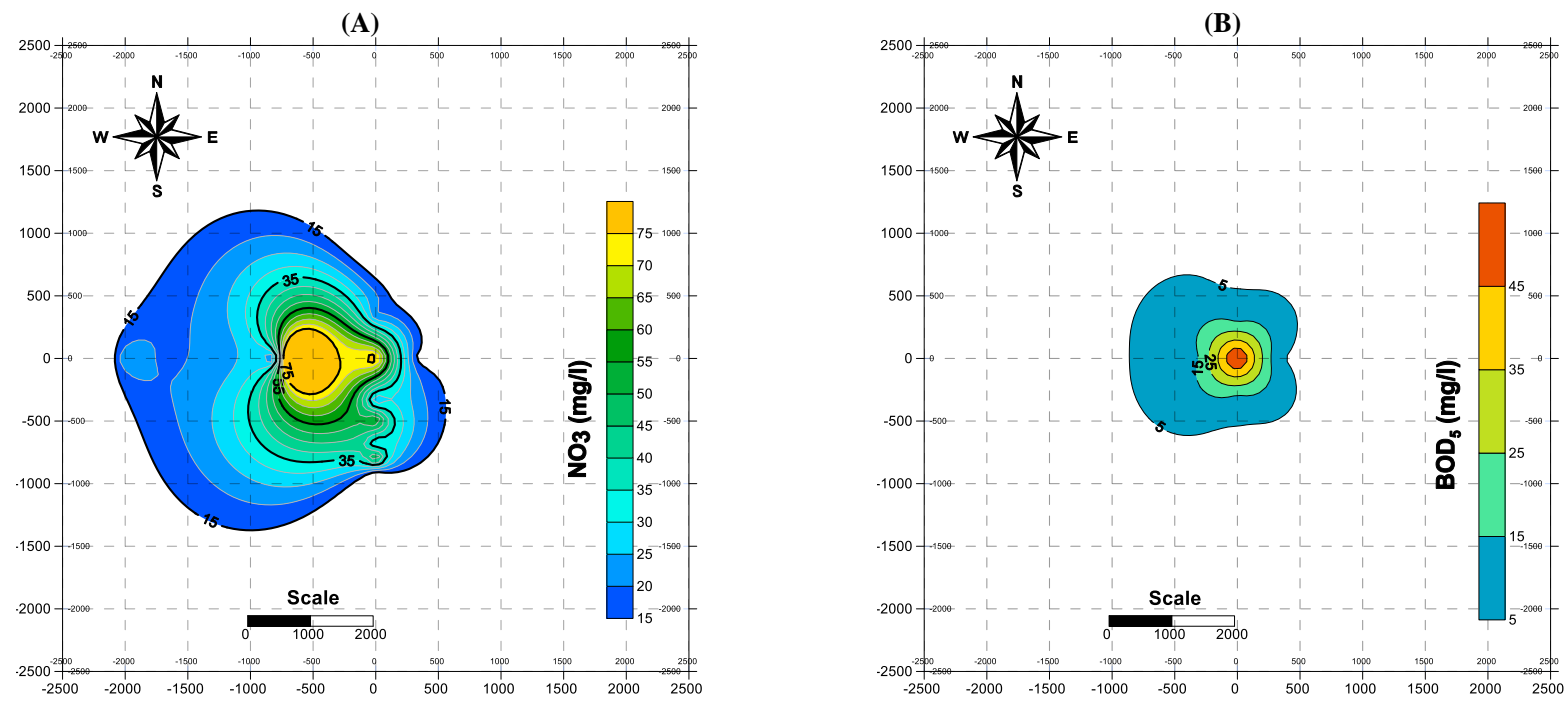

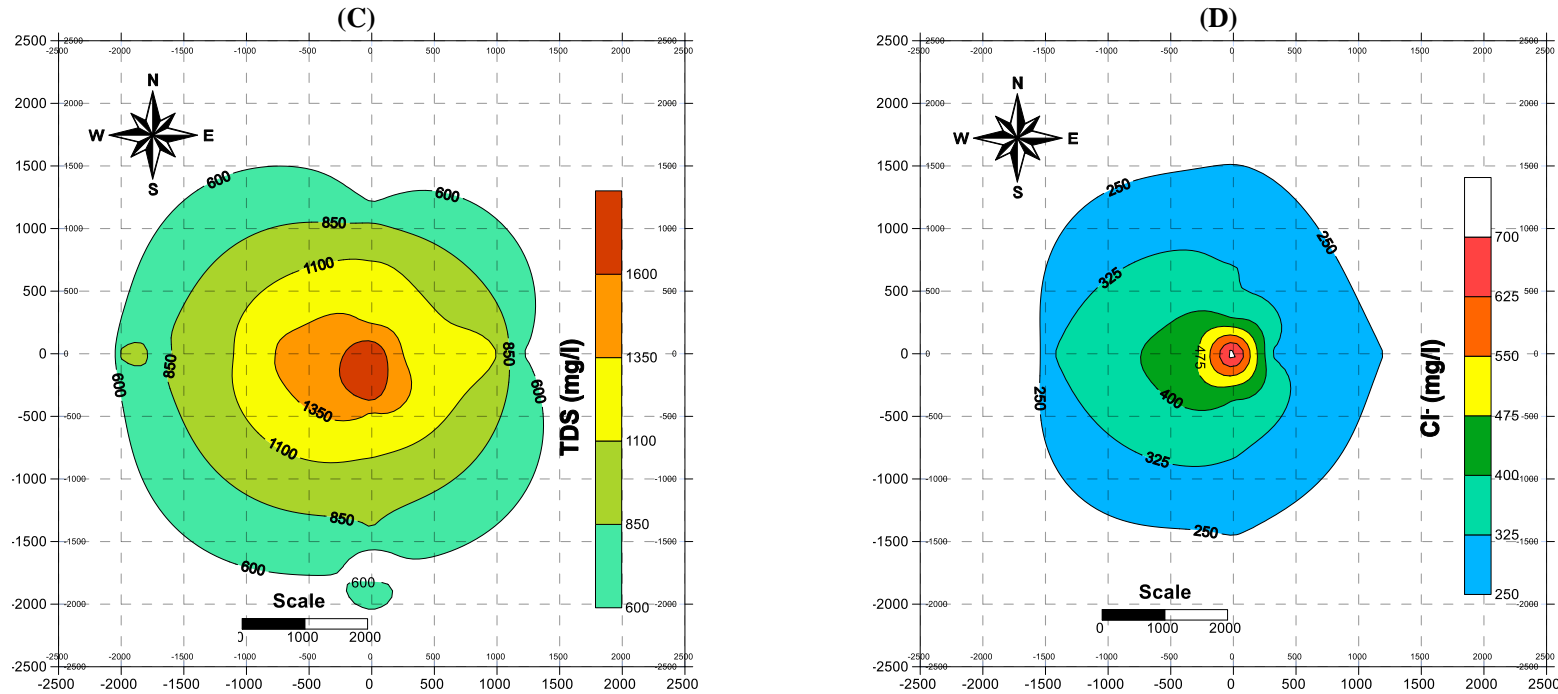

Fig. 3: Dispersion of Contamination for: (A) Nitrate; (B) BOD; (C) TDS; and (D) Chloride.

The periodic diagnosis of the infiltration capacity for the infiltration basin is of the main concern to ensure the integrity of the recharging process over the operational period. The demonstrated data of the infiltration rates in Fig. 4 show a significant decrease in the infiltration efficiency over six years of operation from 2011 until the year 2017. The reduction in the range of infiltration rate is obvious in basin no. (1) which mainly contains the lowest infiltration rate among the other infiltration basins. The range of the infiltration rate for the whole basins fluctuated between 0.1 and 3.1 meters per day. Since the year of 2015, the decline in the basin's infiltration capacity has been regarded as one of the most operational problems that face the workability and the sustainability of the artificial recharge of the treated wastewater infiltration basins of NGEST.

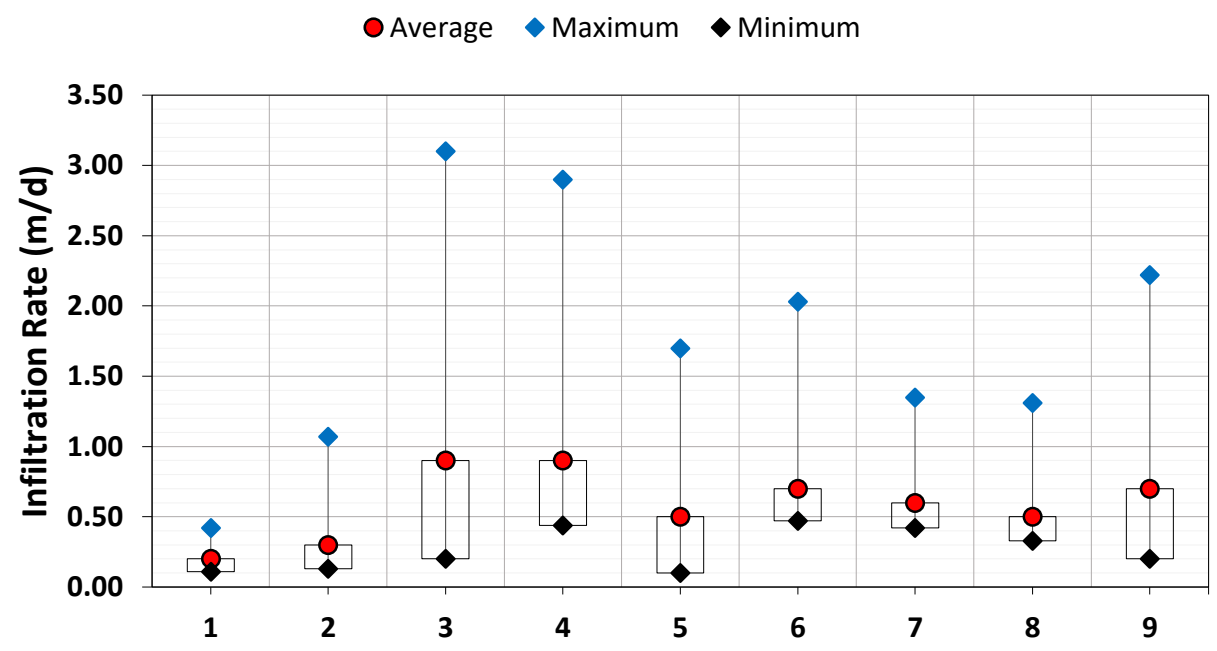

Basin Number

Fig. 4: Measured Infiltration Rate for All Basins 2011-2017 (PWA, 2016).

The estimated total amount of treated wastewater that was recharged into the groundwater through the nine infiltration basins from April 2009 until March 2013 was about 19 million cubic meters with an average flow of about 8400 cubic meters per day. This amount of treated wastewater that was recharged represents a high load of accumulated TSS and BOD and other impurities that absolutely decreases the infiltration efficiency due to the clogging in the infiltration basins. The conventional maintenance activities should be addressed and take place at the basins by ploughing the top surface of the soil and stop the pumping at certain basins for certain periods in order to ensure the effective recovery of the infiltration capacity of the basins.

\section{Material and methods}

Investigating the current infiltration capacity of the nine infiltration basins of the NGEST is the main purpose of this study. Therefore, sample collection and field experimental study using a double-ring infiltrometer was prepared in the basins area to evaluate the actual existing infiltration capacity in order to recommend proper mitigation measures to enhance the infiltration rate to reach the desired value. The area of the infiltration basin of no. (3) was selected to take samples and to perform the experimental analysis because the data of the infiltration rates are distributed on a larger range than other basins and this means that the infiltration rates in the designated basin have more outliers and this gives the advantage to basin no.(3) to be a good representative for the all expected infiltration rates that may take place during the infiltration processes. Hence, two spots, Fig. 5, were selected within basin no. (3) for the study. The first spot, i.e. point (A), was designated to be in the north-eastern part while the other spot, i.e. point (B), was chosen at the north-western part of the basin. 

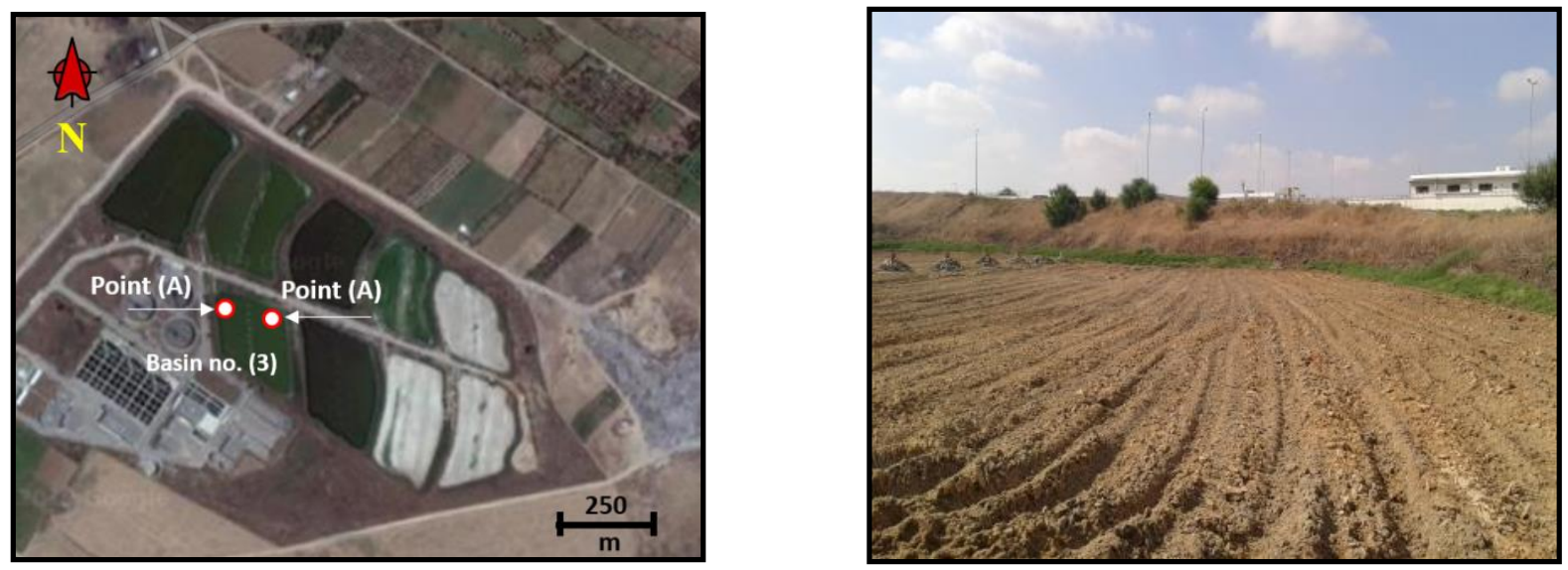

Fig. 5: Location of the Sample Collecting Area of Basin Number (3).

The nature of the surface soil in the Gaza Strip is classified as a kurkar group (sandy), shown in Fig. 6.a; thus, in order to characterize the type and nature of basin soil layer, a number of soil samples were collected from the two points. The spot of the earth was excavated to a depth of $20 \mathrm{~cm}$ and samples of soils were gathered, packaged using plastic bags and samples and were transported to the laboratory for the analysis of bulk density, sieve analysis, and water content. Furthermore, the type of water that is used in the infiltration process affects significantly the capacity and the rate of infiltration. Hence, collected samples of freshwater from a water well belongs to the wastewater treatment plant as well as collecting samples of treated wastewater from the basin no. (3) were maintained in glass bottles and transported to the laboratory to analyse the parameters of acidity (PH), Biological oxygen demand (BOD5), Total dissolved solids (TDS) and total suspended solids (TSS). In the laboratory, the soil samples were weighted, heated in the oven and analyzed using sieve analysis to specify the type of soil and the water content. Regarding the onsite investigation, the infiltration rate was examined using a double infiltration infiltrometer which consists of an outer and an inner iron rings with a diameter of $30 \mathrm{~cm}$ for the inner ring and $60 \mathrm{~cm}$ for the outer one as shown in Fig. 6. b, c.

(A)

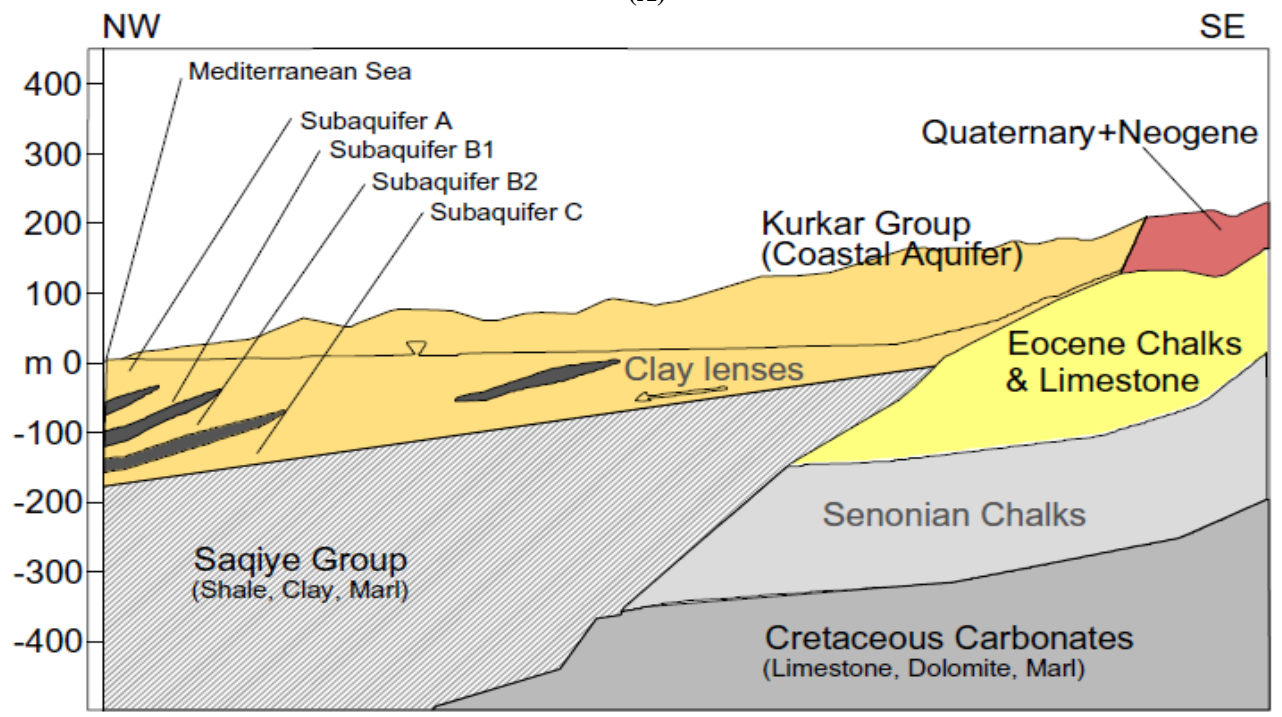

(B)

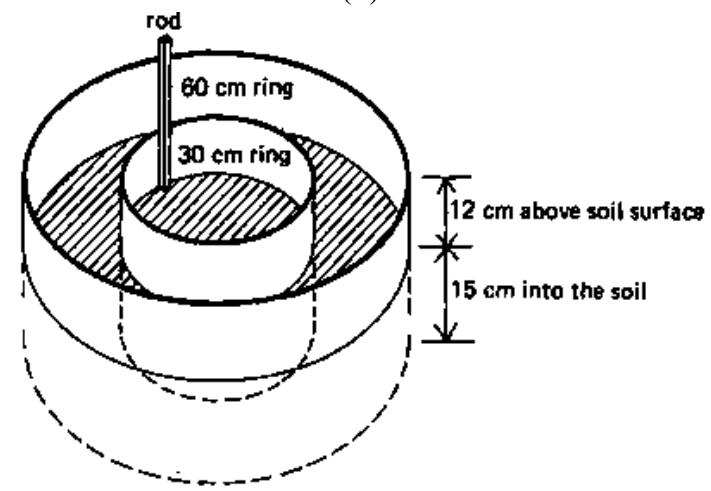

(C)

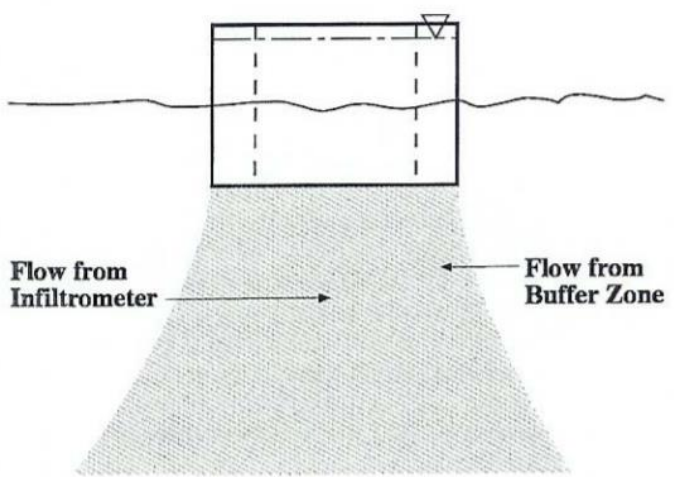

Fig. 6: (A) Geological Section of the Soil Profile (Greitzer, 1967); (B) Double Ring Infiltrometer (Minton, 2002); (C) Infiltration Pattern.

At the testing spots, the surface of the earth was cleaned from impurities and the rings were placed and fixed into the soil at a depth of 15 $\mathrm{cm}$. Afterward, the experimental test trials were performed twice at the two points (A) and (B) by using the freshwater and treated wastewater. For each trial, the water was poured at two stages inside the inner and the outer ring. At the first stage, the rings were filled to a height of about 7.00 to $10 \mathrm{~cm}$ and after that, the second stage is performed by adding water until reaching a height of $18 \mathrm{~cm}$. Consequently, 
to keep the original water level constant, the drop in the water level at the inner ring was supplementing and recording every 1.00 to 2.00 minutes. Continuously, the test was kept in the process until reaching the saturation point, where the drop in water level became constant over the same time interval. Based on that and by measuring and recording the water drop over a period of time, the speed at which the water moves through the soil was determined as the infiltration rate.

\section{Result analysis and discussion}

Reusing treated wastewater is the main water practice that is applied in the northern part of the Gaza Strip for the purposes of irrigation for the recharging of the groundwater aquifer. However, the nature of the soil and the infiltration capacity are changed due to the infiltration activities using treated wastewater. Diagnosing of the operational status of the treated wastewater infiltration basins for the NGEST project has been prepared on the basis of soil and water analysis as well as the characterizing of the in-situ infiltration capacity at the previously mentioned two spots at basin no. (3). The sieve analysis for the collected soil samples, depicted in Fig. 7, shows some different properties for the soil at point (A) and that of point (B).

(A)

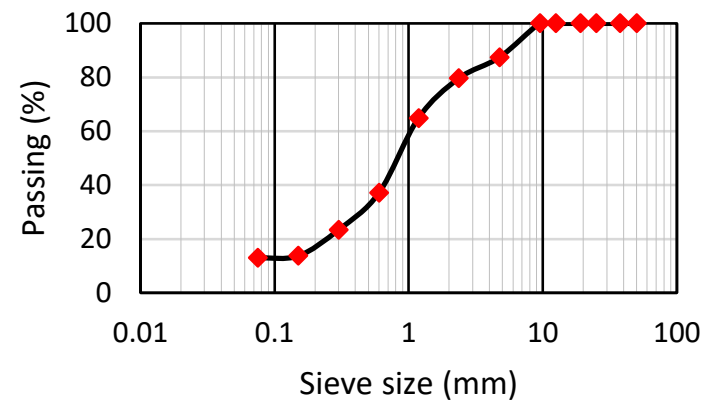

(B)

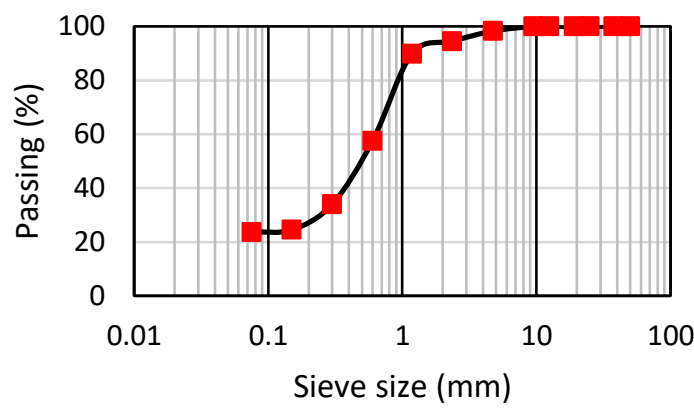

Fig. 7: Soil Sieve Analysis: (A) North-Eastern Point (A); (B) North-Western Point (B).

As shown in the sieve analysis test, the quantity of fine materials that passed from the sieve number (200) at the point (A) is lower than the quantity of fine materials at point (B) where the content of fine materials was $13 \%$ and $23.70 \%$ at points (A) and (B), respectively. Based on that, the soil bulk densities were 1544 and $1873 \mathrm{~kg} / \mathrm{m} 3$ points (A) and (B), respectively. The water content at point (A) was $7.80 \%$ which means that this point is under drought more than that of point (B) with a water content of $11.10 \%$. The characterization analysis for the quality of the groundwater shows high quality in the location of the infiltration basins where the laboratory tests showed no evidence about the contents of total suspended solids (TSS) and biological oxygen demand (BOD). The groundwater is neutral with a PH of 6.90 and total dissolved solids (TDS) of $1600 \mathrm{mg} / \mathrm{l}$. From another side, the quality of the treated wastewater was within the acceptable designated limits by the Palestinian Standard (PS) where the contents of TDS, TSS, COD, and BOD were on average 1800, 35, 80 and $15 \mathrm{mg} / \mathrm{l}$, respectively. The in-situ test results of the double ring infiltrometer are performed to determine the infiltration capacity at infiltration basins. The infiltration rates at the two points (A) and (B) were performed using freshwater and wastewater in order to compare the infiltration rate in the case of pure water as well as the treated wastewater as shown in Fig. 8. The figures show a better infiltration rate using freshwater while the use of treated wastewater showed a lower infiltration rate.

(A)

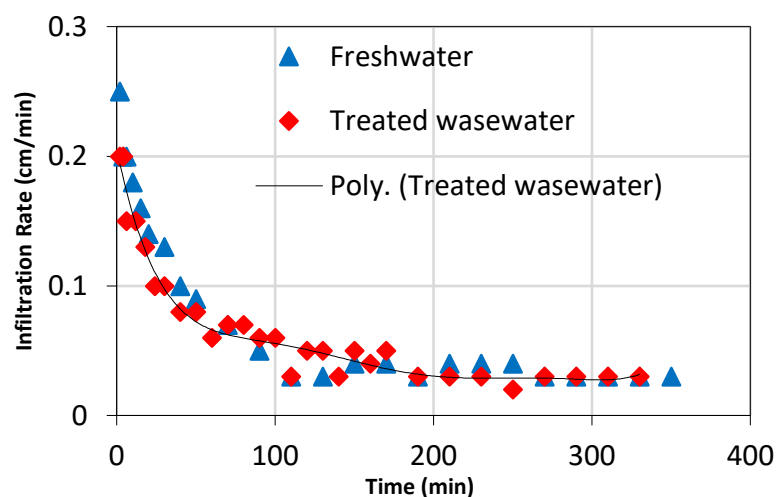

(B)

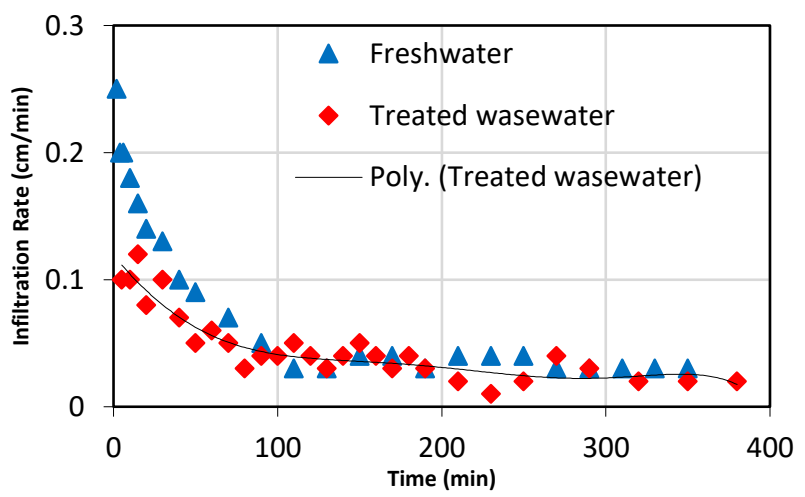

Fig. 8: Soil Sieve Analysis: (A) North-Eastern Point; (B) North-Western Point.

The infiltration rate at the North-Eastern spot of point (A) exhibited better initial and saturated infiltration rates in comparison to the soil at the North-Western spot of point (B), where the initial infiltration rates were 2.88 and 1.73 meters per day, respectively. Furthermore, the saturated infiltration rates were approximately similar to 0.43 and 0.29 meters per day for point (A) and point (B), respectively. Mostly, it can be generalized that the in situ diagnostic assessment for the infiltration capacity of the northern Gaza groundwater infiltration basins shows that the soil classification is silty sand and the infiltration rates range between about 3 and 0.3 meters per day.

\section{Conclusion}

The source of treated wastewater is considered as a promising input to the water cycle. In the Gaza Strip, the treated wastewater is a sustainable water resource to cease the deterioration in the groundwater due to excessive subtraction and low recharge. Thus, the infiltration 
basins in the northern part of Gaza provide a proper mitigation measure to the aquifer. However, the reducing infiltration capacity in the infiltration basins that happens due to the use of the partially treated wastewater is one of the main problems of artificial recharge, and this happens as a result of the ingathering of suspended solids and the organic load, and the poor maintenance .Thus, the diagnostic assessment for the northern Gaza wastewater infiltration basins indicates that the soil classification is silty sand and the infiltration rates range between about 3 and 0.3 meters per day. The effect of the infiltration process on the groundwater is neglectable at a distance beyond 1,000 meters from the infiltration point.

\section{References}

[1] M. Abualtayef, H. Al-Najjar, K. Qahman, M. Alnajjar, Desalination of seawater in the Gaza Strip: The regional short-term low-volume (STLV) seawater desalination plant of Deir Al-Balah as a case study, Desalination and Water Treatment 141 (2019) 8-22. https://doi.org/10.5004/dwt.2019.23425.

[2] M. Abualtayef, G. Abdel Rahman, I. Snounu, K. Qahman, H. Sirhan. A.K. Seif, Evaluation of the effect of water management interventions on water level of Gaza coastal aquifer, Arabian Journal of Geosciences, 10 (2017) 555. https://doi.org/10.1007/s12517-017-3329-x.

[3] H. Al-Najar H., The Integration of FAO-CropWat model and GIS techniques for estimating irrigation water requirement and its application in the Gaza Strip, Natural Resources, 2 (2011) 146-154. https://doi.org/10.4236/nr.2011.23020.

[4] D. Greitzer, The effect of soil landscape and Quaternary geology on the distribution of saline and freshwater aquifers in the Coastal Plain of Israel. Tahal Ltd., Water Planning for Israel, Israel, 1967

[5] B. Shomar, K. Osenbrück, A. Yahya, Elevated nitrate levels in the groundwater of the Gaza Strip: distribution and sources, Science of the Total Environment, 398 (2008) 164-174. https://doi.org/10.1016/j.scitotenv.2008.02.054.

[6] M.F. Jaramillo, I. Restrepo, Wastewater reuse in agriculture: a review about its limitations and benefits, Sustainability, 9 (2017) 1-19.

[7] G. Minton, Stormwater treatment, Seattle, Washington, 2002. https://doi.org/10.3390/su9101734.

[8] M.H. Sami, N. Abdelmajid, U. Troeger, Impact on Gaza aquifer from recharge with partially treated wastewater, Journal of Water Reuse and Desalination 1 (2011) 36-44. https://doi.org/10.2166/wrd.2011.001.

[9] PCBS, Statistical review on the status of the Palestinian population on the eve of the international population day, Palestinian Central Bureau of Statistics (2017).

[10] PWA, The Gaza emergency technical assistance programme on water supply to the Gaza Strip (GETAP), component 1. The Comparative Study of Options for an Additional Supply of Water for the Gaza Strip (CSO-G) The Updated Final Report (Report 7 of the CSO-G), Palestinian Water Authority (2011).

[11] PWA, Water supply report 2010, Palestinian Water Authority (2012).

[12] PWA. Projects management unit/PMU, progress report, quarter number 33 for the Period 1st Jan-31st March 2013, Palestinian Water Authority (2013).

[13] PWA, Gaza water resources status report, 2013/2014. Palestinian Water Authority, Gaza, Palestine (2014a).

[14] PWA, Environmental and social impact assessment and environmental and social management plan for Gaza water supply and sewage systems improvement project. Palestinian Water Authority, Palestine (2014b).

[15] PWA, Gaza Strip: desalination facility project: necessity, politics and energy. Palestinian Water Authority, Gaza, Palestine (2015).

[16] PWA, Revie of recent groundwater situation around the NGEST. Palestinian Water Authority, Gaza, Palestine (2016).

[17] PS, The Palestinian standards for treated wastewater. Palestinian Standard (2003).

[18] M. Seyam, Y. Moghier, Application of artificial neural networks model as analytical tool for groundwater salinity, Journal of Environmental Protection, 2 (2010) 56-71. https://doi.org/10.4236/jep.2011.21006.

[19] WHO, A compendium of standards for wastewater reuse in the Eastern Mediterranean Region. World Health Organization, Regional Office for the Eastern Mediterranean, Regional Centre for Environmental Health Activities, CEHA (2006).

[20] B. Zhang, Z. He, Improving water desalination by hydraulically coupling an osmotic microbial fuel cell with amicrobial desalination cell, Journal of Membrane Science, 441 (2013) 18-24. https://doi.org/10.1016/j.memsci.2013.04.005. 